\title{
Effect of Smoking and Periodontal Diseases on Salivary Glycoconjugates and Oxidative Stress Markers-A Comparative Study
}

\author{
Bhagyalekshmi $\mathbf{M}^{1 *}$, Seba Abraham² \\ ${ }^{1}$ Consultant Periodontist, India \\ ${ }^{2}$ Professor and Head of the Department PMS College of Dental Science and Research, India \\ *Corresponding Author: Bhagyalekshmi M, Consultant Periodontist, India; \\ Email: bhagyalekshmirajesh511@gmail.com
}

Received Date: 09-03-2021; Accepted Date: 29-03-2021; Published Date: 07-04-2021

Copyright $^{\odot} 2021$ by Bhagyalekshmi M, et al. All rights reserved. This is an open access article distributed under the terms of the Creative Commons Attribution License, which permits unrestricted use, distribution and reproduction in any medium, provided the original author and source are credited.

\begin{abstract}
Background and Objectives: The most important feature in periodontal disease is degradation of extracellular matrix, resulting in elevated levels of various salivary biomarkers in periodontal diseases. Smoking results in oxidative stress as a result of imbalance between Reactive Oxygen Species (ROS) and antioxidants. The present study was intendent to assess and compare the levels of salivary glycoconjugates, oxidative stress markers and transforming growth factor $\beta 1$ (TGF- $\beta 1$ ) levels in periodontally healthy and chronic periodontitis subjects with and without smoking habits.
\end{abstract}

Methods: A total of 100 subjects of age between 20 to 60 years were selected and equally divided among the four groups. The four groups were group 1 (periodontally healthy nonsmokers), group 2 (periodontally healthy smokers), group 3 (chronic periodontitis nonsmokers) and group 4 (chronic periodontitis smokers). Saliva samples were collected from all the four groups. The biochemical parameters assessed include Free Sialic Acid, Protein Bound Sialic Acid, L-Fucose, Total proteins, Total hexose, Superoxide Dismutase, Malondialdehyde and Transforming Growth Factor-Beta1 (TGF- $\beta 1$ ).

Results: The analysis of variance showed that there exists a statistically significant differences in the mean value of salivary total proteins $(p<0.05)$, total hexose $(p<0.01)$, Superoxide

Bhagyalekshmi M | Volume 2; Issue 1 (2021) | JDHOR-2(1)-024 | Data Article

Citation: Bhagyalekshmi M, et al. Effect of Smoking and Periodontal Diseases on Salivary Glycoconjugates and Oxidative Stress Markers-A Comparative Study. J Dental Health Oral Res. 2021;2(1):1-13. 
Dismutase $(\mathrm{p}<0.01)$, Malondialdehyde $(\mathrm{p}<0.05)$, Transforming Growth Factor $\beta 1(\mathrm{p}<0.01)$ among the four groups.

Conclusions: The present study highlights the need for incorporating smoking cessation programs in routine periodontal therapy. The alterations in the levels of glycoconjugates are observed in other pathological conditions like rheumatoid arthritis, cirrhosis, cancer, cardiovascular diseases. These potent biomarkers mapped way for screening other inflammatory conditions too.

\section{Keywords}

Periodontitis; Salivary Glycoconjugates; Oxidative Stress Markers; Transforming Growth Factor B1; Smoking

\section{Introduction}

Periodontitis is currently considered as an inflammatory disease initiated by the complex interactions among plaque bacteria, host's genetic factors, and environmental risk factors [1]. Periodontal disease is characterized by abnormal host immune inflammatory response to bacteria resulting in excessive release of proteolytic enzymes and Reactive Oxygen Species (ROS) which may lead to direct or indirect tissue damage due to oxidative stress [2]. Normally there is a balance between ROS and antioxidants that may be disturbed by a variety of factors, including smoking. Smoking is considered as an environmental modifiable risk factor resulting in high incidence of periodontal tissue destruction [3]. when smokers with and without periodontitis were compared it was reported that smokers with periodontitis have more smoking-related diseases, such as coronary artery disease and type 1 diabetes than smokers without periodontitis. Thus, periodontitis is considered as a predictor for many systemic diseases in smokers [4]. Both periodontitis and periodontitis accelerated by the impact of smoking can lead to the increased production of ROS and end in oxidative stress. Protection against these species is provided by antioxidants that may be in the form of enzymes like Superoxide Dismutase (SOD), catalase and glutathione peroxidase.

The most important feature in periodontal disease is accelerated connective tissue destruction, more specifically degradation of Extracellular Matrix (ECM) [5]. These results in elevated levels of various salivary biomarkers in periodontal disease. Saliva is a novel diagnostic body fluid that contains specific, soluble biological markers that are specific to the unique physiological aspects of periodontal diseases [6]. Periodontal disease is traditionally diagnosed by clinical and radiographic parameters. Although these parameters can detect evidence from

Bhagyalekshmi M | Volume 2; Issue 1 (2021) | JDHOR-2(1)-024 | Data Article

Citation: Bhagyalekshmi M, et al. Effect of Smoking and Periodontal Diseases on Salivary Glycoconjugates and Oxidative Stress Markers-A Comparative Study. J Dental Health Oral Res. 2021;2(1):1-13. 
past disease, they provide only limited information about susceptibility of patient to future periodontal problems.

Glycoconjugates are biologically important molecules expressed on the cell surface with diverse functions. The carbohydrate antigens carried by glycoconjugates mainly present on the cell surface not only serve as marker molecules but also serve as functional molecules. Several studies have revealed that glycoconjugates play key roles in infectious disease like chronic periodontitis. Transforming Growth Factor $\beta 1$ (TGF- $\beta 1$ ), a multifunctional cytokine plays a prominent role in connective tissue remodelling and regulation of various immunomodulatory processes [7]. There is ease in sampling and analysing of TGF- $\beta 1$ in saliva and may serve to predict the progression of periodontal diseases [8]. In smokers, nicotine has the property of regulating the release of basic fibroblast growth factor and TGF- $\beta 1$ [9]. Salivary glycoconjugates, Transforming Growth Factor Beta 1 (TGF- $\beta 1$ ) and oxidative stress markers are relatively less studied among smokers. Hence, the present study was planned to assess and compare the levels of salivary glycoconjugates, oxidative stress markers and Transforming Growth Factor $\beta 1$ (TGF- $\beta 1$ ) levels in periodontally healthy and chronic periodontitis subjects with and without smoking habits.

\section{Materials and Methods}

The present study was conducted in the department of Periodontics, PMS College of Dental Science and Research, Vattapara, Thiruvananthapuram between March 2018 and April 2019. The study started after getting ethical clearance from the Ethical Committee of the Institute, IEC NO: PMS/IEC/2017/08. One hundred male subjects were recruited. The subjects ranged in age from 20 to 60 years and were categorized into four groups based on periodontal health status and smoking habits as follows:

Group 1 consisted of 25 subjects who were periodontally healthy non-smokers

Group 2 consisted of 25 subjects who were periodontally healthy smokers

Group 3 consisted of 25 subjects who were non-smokers with chronic periodontitis

Group 4 consisted of 25 subjects who were smokers with chronic periodontitis

Clinical evaluation was done in the department of Periodontics. Detection of levels of salivary glycoconjugates, oxidative stress markers and Transforming Growth Factor (TGF- $\beta 1$ ) levels were done at Biogenix Research Centre, Trivandrum. Before the study, the purpose and design of the study was explained to all the subjects and an informed consent was obtained. Those patients who consumed more than five cigarettes/beedi per day since the past six months were included in the smoker's categories and chronic generalized periodontitis subjects were diagnosed according to criteria given by American Academy of Periodontology 1999 classification. Only those subjects who fulfilled all inclusion and exclusion criteria were

Bhagyalekshmi M | Volume 2; Issue 1 (2021) | JDHOR-2(1)-024 | Data Article

Citation: Bhagyalekshmi M, et al. Effect of Smoking and Periodontal Diseases on Salivary

Glycoconjugates and Oxidative Stress Markers-A Comparative Study. J Dental Health Oral Res.

2021;2(1):1-13.

DOI: http://dx.doi.org/10.46889/JDHOR.2021.2107 
formally enrolled into the study. Patients who had taken antibiotics or anti-inflammatory drugs for the past 3 months prior to the study, patients with history of periodontal therapy during the past 6 months and those patients with systemic diseases were excluded from the study.

The saliva samples were collected before clinical measurements, between 9-11 am. Subjects were asked to rinse their mouth thoroughly with distilled water, to remove any food debris and then to spit effortlessly into sterile disposable eppendorf tubes. Collected saliva was placed in a mini-cooler under $-20^{\circ} \mathrm{C}$ until it was transferred to laboratory for biochemical analysis. All biochemical analyses were performed in Biogenix Research Centre (BRMAS), REG NO: 2427/14; Trivandrum.

Clinical measurements were performed immediately after unstimulated whole saliva collection. Data recorded included age, sex, medical status, habits, family history, dentition status, and detailed periodontal examination. After thorough medical and dental examination, a detailed periodontal examination which include plaque index, Gingival Index, Probing Pocket Depth (PPD) and Clinical Attachment Loss (CAL) were done and the readings were recorded to the nearest millimetre using UNC -15 periodontal probe. One trained examiner obtained all the measurements to reduce intra-examiner variability.

\section{Biomarker Analysis}

\section{Estimation of Sialic Acid}

Sialic acid was estimated by the method of Yao, et al., [10]. The method of acidic ninhydrin reaction was used to determine the amount of protein bound sialic acid and free sialic acid. The samples were treated with ethanol for precipitating proteins. The reaction mixture contains $350 \mu 1$ of saliva samples, $350 \mu 1$ of glacial acetic acid and $350 \mu 1$ of acid ninhydrin reagent. It was heated for 10 minutes during a boiling water bath. Then the mixture was rapidly chilled in an ice bath. The absorbance was read at $470 \mathrm{~nm}$ using a UV visible spectrophotometer. The concentration of protein bound sialic acid was obtained from the precipitate and the concentration of free sialic acid was obtained from the supernatant compared with $\mathrm{N}$-acetyl Nuraminic acid.

\section{Estimation of Fucose}

Fucose in the saliva samples was estimated by the method of Dische and Shettles (1948). Reagents include sulphuric acid reagent (Conc. sulphuric acid $\left(\mathrm{H}_{2} \mathrm{SO}_{4}\right)$ and distilled water were mixed in the ratio of 6:1) and cysteine hydrochloride reagent (3\% cysteine hydrochloride in water, $0.1 \mathrm{~N}$ Sodium Hydroxide $(\mathrm{NaOH}))$. To $2.2 \mathrm{ml}$ of saliva samples, $4.8 \mathrm{ml}$ of Sulphuric

Bhagyalekshmi M | Volume 2; Issue 1 (2021) | JDHOR-2(1)-024 | Data Article

Citation: Bhagyalekshmi M, et al. Effect of Smoking and Periodontal Diseases on Salivary

Glycoconjugates and Oxidative Stress Markers-A Comparative Study. J Dental Health Oral Res.

2021;2(1):1-13.

DOI: http://dx.doi.org/10.46889/JDHOR.2021.2107 
acid reagent was added and heated in a boiling water bath for 3 minutes. The sample was cooled and $0.1 \mathrm{ml}$ of cysteine hydrochloride reagent was added, $0.5 \mathrm{ml}$ of $0.1 \mathrm{~N} \mathrm{NaOH}$ was also treated as blank. After 25 minutes, the absorbance was measured at $393 \mathrm{~nm}$ and $430 \mathrm{~nm}$. Fucose content was expressed as $\mathrm{mg} / \mathrm{dL}$ of $\mathrm{mg} / \mathrm{ml}$ saliva.

\section{Determination of Total Hexoses}

Total hexoses in the saliva samples were estimated by the method of Niebes (1972). Reagents include Orcinol (sulphuric acid mixture: $1.6 \mathrm{~g}$ of orcinol was dissolved in $100 \mathrm{ml}$ of water). 1 $\mathrm{ml}$ of this solution was mixed with $7.5 \mathrm{ml}$ of $\mathrm{H} 2 \mathrm{SO} 4: \mathrm{H} 2 \mathrm{O}$ mixture (3:2 v/v) (Freshly prepared) and $2.5 \mathrm{mg}$ of Galactose and mannose was dissolved in $100 \mathrm{ml}$ of water. (Concentration- 100 $\mathrm{mg} / \mathrm{ml}$ ). $0.2 \mathrm{ml}$ of saliva sample was mixed with $8.5 \mathrm{ml}$ of orcinol- $\mathrm{H}_{2} \mathrm{SO}_{4}$. The tubes were then heated at $80^{\circ} \mathrm{C}$ for 15 minutes, cooled and read at $540 \mathrm{~nm}$ after 20 minutes. Standard and blank containing $0.1 \mathrm{ml}$ of $0.2 \mathrm{~N} \mathrm{H} 2 \mathrm{SO} 4$ were also done. Total hexose content was expressed as $\mathrm{mg} / \mathrm{dL}$ of $\mathrm{mg} / \mathrm{ml}$ saliva.

\section{Determination of Protein Estimation by Lowry's Method}

The blue colour developed by the reduction of the phoshomolybdicphosphotungstic components in the Folin - Ciocalteau reagent by the amino acids tyrosine and tryptophan present in the protein plus the color formed by the biuret reaction of the protein with the alkaline cupric tartarate are measured using Lowry's method. Reagents include $2 \%$ sodium carbonate in $0.1 \mathrm{~N}$ sodium hydroxide (Reagent A), $0.5 \%$ Copper sulphate in $1 \%$ potassium sodium tartrate (Reagent B), Alkaline copper solution - Mixed $50 \mathrm{ml}$ of A and $1 \mathrm{ml}$ of B prior to use (Reagent C), Folin - Ciocalteau reagent (SRL) and protein solution: Weighed accurately $50 \mathrm{mg}$ of bovine serum albumin (Fraction V) and dissolved in distilled water and made up to $50 \mathrm{ml}$ in a standard flask. $0.1 \mathrm{ml}$ of saliva samples was taken and made up the volume to $1 \mathrm{ml} .5 \mathrm{ml}$ of reagent $\mathrm{C}$ was added to each tube including the blank (water), mixed well and incubated at $37^{\circ} \mathrm{C}$ for 3 minutes. Then $0.5 \mathrm{ml}$ of Folin-Ciocalteau reagent was added, mixed well and incubated at $37^{\circ} \mathrm{C}$ for 3 minutes. Blue color was developed and absorbance measured at $660 \mathrm{~nm}$. A standard graph plotted and calculated the amount of protein in the sample.

\section{Determination of Super Oxide Dismutase (SOD)}

The enzyme superoxide dismutase catalyses the dismutation of superoxide into oxygen and $\mathrm{H}_{2} \mathrm{O}_{2}$. 50 $\mu$ l saliva samples were added to the reaction mixture which contains $50 \mathrm{~mm}$ phosphate buffer (7.8), $45 \mu \mathrm{m}$ methionine, $5.3 \mathrm{~mm}$ riboflavin and $84 \mu \mathrm{m}$ potassium ferric cyanide. The tubes were then incubated at $25^{\circ} \mathrm{C}$ for 10 minutes and the absorbance was read on spectrophotometer at $600 \mathrm{~nm}$.

Bhagyalekshmi M | Volume 2; Issue 1 (2021) | JDHOR-2(1)-024 | Data Article

Citation: Bhagyalekshmi M, et al. Effect of Smoking and Periodontal Diseases on Salivary

Glycoconjugates and Oxidative Stress Markers-A Comparative Study. J Dental Health Oral Res.

2021;2(1):1-13.

DOI: http://dx.doi.org/10.46889/JDHOR.2021.2107 


\section{Determination of Malondialdehyde (MDA)}

Lipid peroxidation referred as the oxidative degradation of lipids. It was the method whereby free radicals "steal" electrons from the lipids within the cell wall leading to cell damage. Polyunsaturated carboxylic acid peroxides generate Malondialdehyde (MDA) upon decomposition. $50 \mu 1$ of saliva samples were added with $500 \mu 1$ of $70 \%$ alcohol and $1 \mathrm{ml} 1 \%$ TBA. Then all the tubes were kept in a boiling water bath for 20 minutes. After cooling to room temperature, added $50 \mu 1$ of acetone to all the test tubes. Absorbance of the sample was read at $535 \mathrm{~nm}$ against the blank that contains no saliva sample.

\section{Estimation of TGF B-1 ELISA (KIT METHOD)}

The quantitative measurement of Human TGF $\beta$-1 Elisa was estimated using ELISA KIT (Immune tag: catalogue no- ITEH0287).

\section{Statistical Methodology}

Statistical analyses were performed by statistical software package SPSS, version 20.0. Data was entered into MS Excel, a component of MS Office software. Primary data analysis was carried out. Patient characteristics were described in terms of mean value and standard deviation. One-way ANOVA with post hoc test was used to compare quantitative parameters among categories. Karl Pearson correlation coefficient carried out to assess the correlation between quantitative parameters. For all statistical interpretations, $\mathrm{p}<0.05$ was considered the threshold for statistical significance.

\section{Results}

In the present study, smokers were compared to non-smokers with respect to the baseline characteristics of clinical parameters like gingival index, plaque index, pocket depth and attachment loss and the levels of salivary glycoconjugates, oxidative stress markers and Transforming Growth Factor $\beta 1$ (TGF- $\beta 1$ ) in periodontally healthy and chronic periodontitis subjects. Scores of all clinical parameters (mean $\pm \mathrm{SD}$ ) where found to be significant in all the four groups (Table 1). Scheffe Multiple Comparisons among groups were done (Table 1). The graphical representations were depicted in Fig. 1.

The levels of Free Sialic Acid (FSA), Protein Bound Sialic Acid (PBSA), L-Fucose, Total proteins, Total hexose, Superoxide Dismutase (SOD), Malondialdehyde (MDA) and Transforming Growth Factor-Betal (TGF- $\beta 1$ ) were compared among the four groups (Table

Bhagyalekshmi M | Volume 2; Issue 1 (2021) | JDHOR-2(1)-024 | Data Article

Citation: Bhagyalekshmi M, et al. Effect of Smoking and Periodontal Diseases on Salivary Glycoconjugates and Oxidative Stress Markers-A Comparative Study. J Dental Health Oral Res. 2021;2(1):1-13. 
2). Scores of all biochemical parameters (mean \pm SD) where found to be significant in all the four groups except the case of parameters like free sialic acid, protein bound sialic acid and Lfucose. Scheffe multiple comparisons among groups were done and are listed in Table 2. The graphical representations were depicted in Fig. 2.

Correlation of clinical parameters and biochemical parameters were done using Pearson's correlation and expressed by Pearson's correlation coefficient. There exists significant positive correlation $(\mathrm{r}=0.441, \mathrm{p}=0.027)$ between total hexose and gingival index in group 1 , a positive correlation $(\mathrm{r}=0.558 * * \mathrm{P}=0.004)$ between protein bound sialic acid and plaque index and a positive correlation $\left(\mathrm{r}=0.455^{*}, \mathrm{p}=0.022\right)$ between total proteins and plaque index in group 2 . There was no statistically significant correlation between biochemical parameters and clinical parameters in group 4.

\begin{tabular}{|l|l|l|l|}
\hline Groups & Plaque index & Gingival index & Pocket depth \\
\hline Group 1 & $1.03 \pm 0.24 * *$ & $1.20 \pm 0.56^{* *}$ & $2.33 \pm 0.35^{* *}$ \\
\hline Group 2 & $1.36 \pm 0.38^{* *}$ & $0.72 \pm 0.35^{* *}$ & $2.72 \pm 0.31^{* *}$ \\
\hline Group 3 & $2.04 \pm 0.21^{* *}$ & $1.95 \pm 0.36^{* *}$ & $7.15 \pm 1.00^{* *}$ \\
\hline Group 4 & $2.10 \pm 0.17^{* *}$ & $1.86 \pm 0.26^{* *}$ & $8.11 \pm 1.20^{* *}$ \\
\hline P value & $\mathrm{p}<0.01$ & $\mathrm{p}<0.01$ & $\mathrm{p}<0.01$ \\
\hline \multicolumn{4}{|c|}{ Scheffe Multiple Comparisons } \\
\hline 1 and 2 & $0.000^{* *}$ & $0.000^{* *}$ & 0.434 \\
\hline 1 and 3 & $0.000^{* *}$ & $0.000^{* *}$ & $0.000^{* *}$ \\
\hline 1 and 4 & $0.000^{* *}$ & $0.000^{* *}$ & $0.000^{* *}$ \\
\hline 2 and 3 & $0.000^{* *}$ & $0.000^{* *}$ & $0.000^{* *}$ \\
\hline 2 and 4 & $0.000^{* *}$ & $0.000^{* *}$ & $0.000^{* *}$ \\
\hline 3 and 4 & 0.922 & 0.879 & $0.000^{* *}$ \\
\hline p<0.01; $* *:-$ Significant at 0.01 level, $*$ significant at 0.05 level \\
\hline
\end{tabular}

Table 1: Comparison of clinical parameters based on groups. 


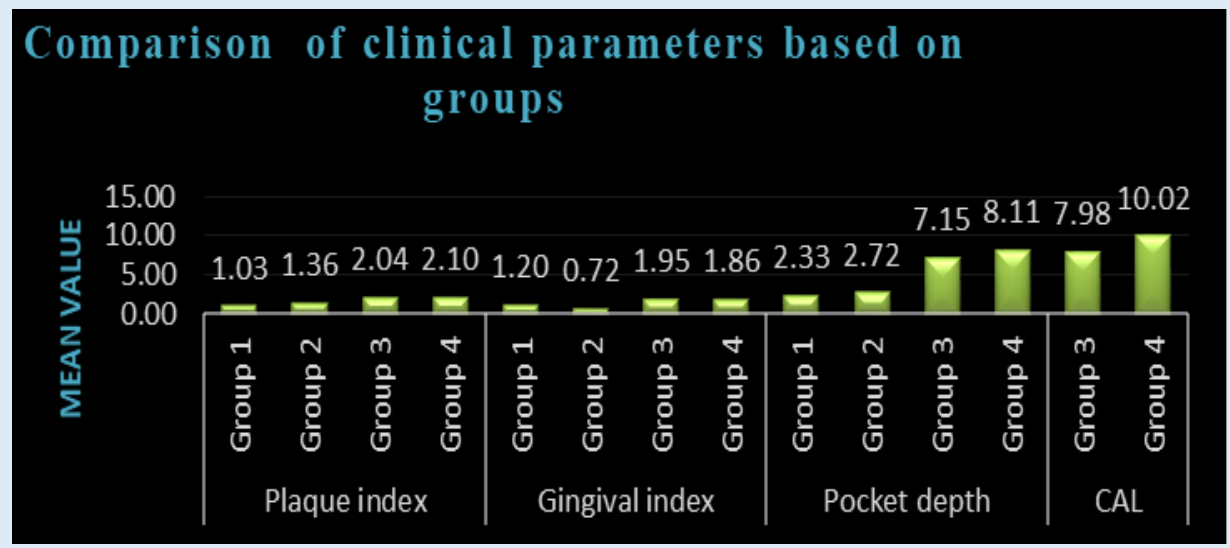

Figure 1: Comparison of clinical parameters based on groups.

\begin{tabular}{|c|c|c|c|c|c|c|c|c|}
\hline Groups & $\begin{array}{l}\text { FSA } \\
(\mathrm{mm})\end{array}$ & PBSA & L-Fucose & $\begin{array}{c}\text { Total } \\
\text { proteins }\end{array}$ & $\begin{array}{l}\text { Total } \\
\text { hexose }\end{array}$ & SOD(IU) & $\begin{array}{c}\operatorname{MDA}(\mu \\
\mathrm{g})\end{array}$ & TGF- $\beta 1$ \\
\hline & & $(\mathrm{mm})$ & (mg/DL) & $(\mu \mathrm{g} / \mathrm{ml})$ & $(\mathrm{mg} / \mathrm{dl})$ & & & (ng/L) \\
\hline Group 1 & $\begin{array}{c}0.52 \pm 0 \\
22\end{array}$ & $0.28 \pm 0.07$ & $2.75 \pm 2.96$ & $\begin{array}{c}1349.7 \pm 215 \\
5\end{array}$ & $\begin{array}{c}7525.4 \pm 2 \\
853.9\end{array}$ & $33.3 \pm 5.6$ & $\begin{array}{c}28.8 \pm 10 \\
.1\end{array}$ & $\begin{array}{c}613.0 \pm 17 \\
8.4\end{array}$ \\
\hline Group 2 & $\begin{array}{c}0.59 \pm 0 \\
31\end{array}$ & $0.30 \pm 0.08$ & $3.08 \pm 2.38$ & $\begin{array}{c}1311.6 \pm 165 \\
3\end{array}$ & $\begin{array}{c}5436.4 \pm 3 \\
827.3\end{array}$ & $29.3 \pm 8.9$ & $\begin{array}{c}36.7 \pm 11 \\
.9\end{array}$ & $\begin{array}{c}611.6 \pm 11 \\
6.2\end{array}$ \\
\hline Group 3 & $\begin{array}{c}0.66 \pm 0 \\
55\end{array}$ & $0.27 \pm 0.07$ & $2.80 \pm 2.08$ & $\begin{array}{c}1463.7 \pm 215 \\
8\end{array}$ & $\begin{array}{c}5063.8 \pm 2 \\
415.7\end{array}$ & $\begin{array}{c}28.4 \pm 10 \\
4\end{array}$ & $\begin{array}{c}36.3 \pm 12 \\
.3\end{array}$ & $\begin{array}{c}677.6 \pm 23 \\
2.7\end{array}$ \\
\hline Group 4 & $\begin{array}{c}0.76 \pm 0 \\
39\end{array}$ & $0.30 \pm 0.10$ & $3.84 \pm 2.60$ & $\begin{array}{c}1295.4 \pm 252 \\
6\end{array}$ & $\begin{array}{c}4461.2 \pm 1 \\
097.3\end{array}$ & $22.5 \pm 7.8$ & $\begin{array}{c}38.1 \pm 13 \\
.5\end{array}$ & $\begin{array}{c}872.1 \pm 24 \\
9.6\end{array}$ \\
\hline$P$ value & 0.172 & 0.459 & 0.394 & $0.029 *$ & $0.001 * *$ & $0.000 * *$ & $0.033^{*}$ & $0.000 * *$ \\
\hline & & & Scheffe I & Iltiple Comp & isons & & & \\
\hline Pair & $\begin{array}{c}\text { Total } \\
\text { proteins }\end{array}$ & $\begin{array}{c}\text { Total } \\
\text { hexose }\end{array}$ & SOD(IU) & $\operatorname{MDA}(\mu \mathrm{g})$ & \multicolumn{4}{|c|}{ TGF- $\beta 1$} \\
\hline & $(\mu \mathrm{g} / \mathrm{ml})$ & $(\mathrm{mg} / \mathrm{dl})$ & & & \multicolumn{4}{|c|}{ (ng/L) } \\
\hline 1 and 2 & 0.941 & 0.069 & 0.417 & 0.153 & \multicolumn{4}{|c|}{1} \\
\hline 1 and 3 & 0.323 & $0.021^{*}$ & 0.243 & 0.184 & \multicolumn{4}{|c|}{0.732} \\
\hline 1 and 4 & 0.849 & $0.002 * *$ & $0.000 * *$ & 0.065 & \multicolumn{4}{|c|}{$0.000^{* *}$} \\
\hline 2 and 3 & 0.106 & 0.972 & 0.987 & 1 & \multicolumn{4}{|c|}{0.719} \\
\hline 2 and 4 & 0.995 & 0.662 & $0.049 *$ & 0.982 & \multicolumn{4}{|c|}{$0.000^{* *}$} \\
\hline 3 and 4 & 0.059 & 0.894 & 0.111 & 0.967 & \multicolumn{4}{|c|}{$0.011^{*}$} \\
\hline
\end{tabular}

Table 2: Comparison of biochemical parameters based on groups. 


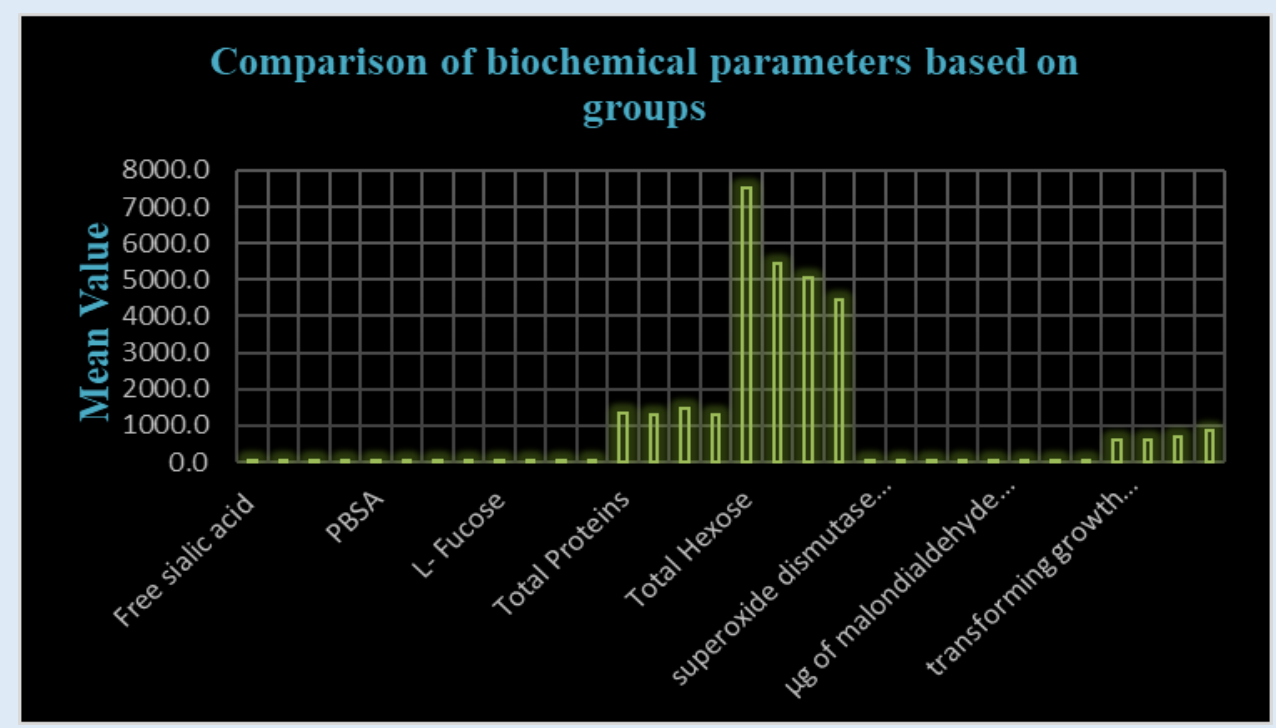

Figure 2: Comparison of biochemical parameters based on groups.

\section{Discussion}

An enormous number of researches has been undergoing on all aspects of periodontitis, including its pathogenesis. A breakthrough on the current paradigm in the pathogenesis of periodontal disease is the new model, "Inflammation-Mediated Polymicrobial-Emergence and Dysbiotic-Exacerbation” (IMPEDE), introduced by Van Dyke TE, et al., 2020 which is based on the central role of inflammation modulating the polymicrobial biofilm. It is well acknowledged that while the etiology of periodontitis is bacterial, the pathogenesis is inflammatory with accelerated connective tissue destruction [11].

As saliva is considered as a reliable, readily collectable by non-invasive methods, and a future promising diagnostic fluid, we opt for saliva as the diagnostic fluid for our present study. Glycoconjugates are biologically important molecule with diverse functions. Several studies have revealed that glycoconjugates play key role in infections and diseases. In this study, the salivary glycoconjugates were assessed and it includes Free Sialic Acid (FSA), Protein Bound Sialic Acid (PBSA), L-Fucose (Fuc), Total proteins (Tp) and Total hexose.

The current study, the mean free sialic acid and protein bound sialic acid values were not statistically significant among the groups. However, Salivary, Free Sialic Acid (FSA) was comparatively elevated in chronic periodontitis patients (group 3) compared to periodontally healthy subjects (group 1) which may be due to the release of different exoglycosidases and mucoproteins during the progression of periodontal inflammation. The present study was in accordance with study conducted by AlSada, et al., and Rathod, et al., who reported that the salivary sialic acid levels in periodontitis subjects were significantly higher compared to

Bhagyalekshmi M | Volume 2; Issue 1 (2021) | JDHOR-2(1)-024 | Data Article

Citation: Bhagyalekshmi M, et al. Effect of Smoking and Periodontal Diseases on Salivary Glycoconjugates and Oxidative Stress Markers-A Comparative Study. J Dental Health Oral Res. 2021;2(1):1-13. 
periodontally healthy subjects [12,13]. The lowest mean PBSA level was in chronic periodontitis non-smokers (group 3) and this may be due to increase sialidase activity by periodontal pathogens which capture the sialic acid [14]. This finding correlate with the previous study by Shetty, et al., who reported that PBSA was decreased in gingivitis and periodontitis [15].

The study also compared the levels of L-Fucose score among groups. Even though the difference was not statistically significant, L-Fucose tends to increase from healthy to periodontitis subjects and this may be due to breakdown of plasma and tissue glycoproteins by the action of lysosomal enzymes during periodontal inflammation. The findings were consistent with previous study by Musa, et al., [16]. L-Fucose was found to be higher among smokers than non- smokers in our study, this was in harmony with the findings of previous study by $\mathrm{S}$ Thompson, et al., who reported that changes occur in fucose metabolism in the case of smokers and heavy drinkers [17].

Salivary total protein is a vital component of saliva as salivary proteins are responsible for the majority of functions of saliva. The results indicated that mean total protein value among groups were statistically significant $(\mathrm{p}<0.05)$. The increased total protein in group 3 may be due to an increased leakage of plasma proteins into saliva during inflammation, enhanced synthesis of acinar proteins by salivary glands and the rise in salivary albumin. Results were coincident with many studies by Henskens, et al., Shetty PK, et al., [15,18]. Mean total protein value among smokers was found to be less (group 2 and 4) when compared to non-smokers, but results were statistically insignificant, this might be due to vasospasm caused by nicotine and decreased salivation and secretion of predominantly small amounts of saliva, rich in proteins, mucins and enzymes. These findings are in comparison to the previous study by Zuabi O, et al., who reported reduction in albumin levels in smokers compared to non-smokers [19]. The study reveals statistically significant difference in mean total hexose value among groups $(\mathrm{P}<0.05)$. The mean salivary total hexose value was found to be decreased among groups from healthy to periodontitis. Decrease may be due to increased level of glycosidases and increased utilization of released oligosaccharides by bacteria. The decrease in total hexose value in saliva appears to be a characteristic feature of oral diseases. This has been addressed previously by Shetty, et al., [15].

Antioxidant enzyme SOD provides protection within the cell against ROS. Statistically significant difference in mean SOD value among groups $(\mathrm{p}<0.05)$ were noted. Smoking results in oxidative stress and results in an imbalance between ROS and antioxidants. The reduction in SOD might be due to the increased concentration of cadmium in the cigarette smoke. Cadmium substitutes the bivalent metals in SOD thus resulting in its inactivation. An increased accumulation of cadmium in blood and decreased levels of SOD enhances periodontal

Bhagyalekshmi M | Volume 2; Issue 1 (2021) | JDHOR-2(1)-024 | Data Article

Citation: Bhagyalekshmi M, et al. Effect of Smoking and Periodontal Diseases on Salivary Glycoconjugates and Oxidative Stress Markers-A Comparative Study. J Dental Health Oral Res. 2021;2(1):1-13. 
destruction. These findings are in agreement with previous studies by Agnihotri R, et al., and Garg N, et al., who also reported that there was a progressive reduction in SOD from healthy non-smokers to heavy smokers [20,21]. Our study indicated that salivary SOD can be used as a predictable diagnostic biomarker for elucidating the pathogenesis of periodontal disease among smokers.

MDA is one of the most frequently used indicator of lipid peroxidase and a reliable biomarker indicating oxidative stress. The mean MDA value among the four groups $(p<0.05)$ were statistically significant and highest mean MDA level was in group 4. The elevated level might be due to increased production of free radicals that in turn leads to lipid peroxidation and ultimately resulting in increased production of MDA. This finding was supported by previous study by Gutteridge, et al., who reported that measuring the levels of LPO products could determine the extent and severity of tissue destruction [22]. The mean salivary MDA levels among smokers were comparatively higher than non-smokers, this might be due to the presence of cigarette smoke which activates the polymorphonuclear neutrophil and elevates the production of free radicals and thereby leading to tissue destruction. Our findings concur with previous study by Garg, et al., [21].

There was statistically significant difference in mean TGF- $\beta 1$ value among the four groups $(\mathrm{p}<0.05)$ and highest mean TGF- $\beta 1$ was in group 4 . TGF $\beta 1$ have an important role in orchestrating the immune response. Increased TGF- $\beta 1$ downregulate an inflammatory response and create a local environment more conducive to growth by periodontal pathogens. These findings are in line with earlier findings of study by Khalaf, et al., who reported higher GCFTGF- $\beta 1$ at sites of inflammation when compared to healthy tissue [8]. However, limited studies were reported in salivary TGF- $\beta 1$ among smokers and its role in the connective tissue breakdown. Low levels of TGF $\beta 1$ activity stimulates inflammation during initial stages of disease progression, and this effect of TGF $\beta 1$ is reversed as inflammation progress. Thus, role of TGF $\beta 1$ alternates between proinflammatory and anti-inflammatory axis to regulate immune inflammatory response and to limit tissue destruction as periodontal disease progress to a more destructive state [23].

The clinical parameters like PI, GI, PPD and CAL were compared between groups and there was statistically significant difference in mean among the four groups $(\mathrm{P}<0.05)$. Smokers with chronic periodontitis exhibited more clinical attachment loss and pocket depth when compared to non-smokers (group 3). The immunosuppressant effect of smoking may have contributed to enhanced susceptibility to periodontitis. It was also observed that smokers showed lower gingival index and higher plaque index when compared to other groups. Our study corresponds to previous study by Zuabi, et al., who also reported that smokers have deep pockets, increased calculus formation but the same or less gingival inflammation [19]. There are contradictory

Bhagyalekshmi M | Volume 2; Issue 1 (2021) | JDHOR-2(1)-024 | Data Article

Citation: Bhagyalekshmi M, et al. Effect of Smoking and Periodontal Diseases on Salivary Glycoconjugates and Oxidative Stress Markers-A Comparative Study. J Dental Health Oral Res. 2021;2(1):1-13. 
studies which reported increased gingival inflammation in smokers compared to non-smokers [24].

Salivary glycoconjugates, SOD, MDA, TGF- $\beta 1$ can be used as a prominent and reliable diagnostic indicator that decode the role of smoking as a risk factor for periodontitis. One of the limitations of our present study was that female populations was not included due to their low prevalence of smoking habits. Other limitations include small sample size, difference in techniques used, and categorization like light smokers and heavy smokers were not incorporated. One of the advantages of this study was the recruitment of periodontally healthy smokers which contributed for better inter and intragroup comparison. Additional longitudinal studies with large sample sizes including female smokers might provide further insight into the effect of smoking on periodontium.

\section{Conclusion}

The present study highlights the need for incorporating smoking cessation programs in routine periodontal therapy. Smoking has a potential negative impact on the health of periodontium and smokers are considered as higher risk category for periodontitis. The role of saliva as a promising and reliable diagnostic tool for predicting the severity and extent of connective tissue destruction in periodontitis is also merited. The alterations in the levels of glycoconjugates are observed in other pathological conditions like rheumatoid arthritis, cirrhosis, cancer, cardiovascular diseases. These potent biomarkers mapped way for screening other inflammatory conditions too. Salivary glycoconjugates, transforming growth factor $\beta 1$ and oxidative stress markers could be considered as potential biomarkers for diagnosis, management and prognosis of periodontal diseases.

\section{Acknowledgments}

Thanks to all study participants for their contributions and staffs and postgraduates of department of periodontology for their support during data collection. Thanks to Biogenix research centre for all the biochemical analysis.

\section{References}

1. Zhang S, Yu N, Arce RM. Periodontal inflammation: Integrating genes and dysbiosis. Periodontol 2000. 2020;82:129-42.

2. Chapple IL, Milward MR, Dietrich T. The prevalence of inflammatory periodontitis is negatively associated with serum antioxidant concentrations. J Nutrition. 2007;137(3):657-64.

3. Sreedevi M, Ramesh A, Dwarakanath C. Periodontal status in smokers and nonsmokers: a clinical, microbiological, and histopathological study. Int Dentistry. 2012;2012.

Bhagyalekshmi M | Volume 2; Issue 1 (2021) | JDHOR-2(1)-024 | Data Article

Citation: Bhagyalekshmi M, et al. Effect of Smoking and Periodontal Diseases on Salivary

Glycoconjugates and Oxidative Stress Markers-A Comparative Study. J Dental Health Oral Res.

2021;2(1):1-13.

DOI: http://dx.doi.org/10.46889/JDHOR.2021.2107 
4. Khouja T, Miller RG, Moore PA, Orchard TJ, Costacou T. Periodontal disease, smoking, cardiovascular complications and mortality in type 1 diabetes. J Diabetes and its Complications. 2019;33(9):603-9.

5. Reynolds JJ, Meikle MC. Mechanisms of connective tissue matrix destruction in periodontitis. Periodontology 2000. 1997;14(1):144-57.

6. Malamud D. Saliva as a diagnostic fluid. Dental Clin. 2011;55(1):159-78.

7. Verrecchia F, Mauviel A. Transforming growth factor- $\beta$ signalling through the Smad pathway: role in extracellular matrix gene expression and regulation. J Investigative Dermatol. 2002;118(2):211-5.

8. Khalaf H, Lönn J, Bengtsson T. Cytokines and chemokines are differentially expressed in patients with periodontitis: possible role for TGF- $\beta 1$ as a marker for disease progression. Cytokine. 2014;67(1):29-35.

9. Cucina A, Corvino V, Sapienza P, Borrelli V, Lucarelli M, Scarpa S, et al. Nicotine regulates basic fibroblastic growth factor and transforming growth factor $\beta 1$ production in endothelial cells. Biochemical and Biophysical Res Communications. 1999;257(2):306-12.

10. Yoa K, Ubuta T, Maauoka N, Kinuta M, Ikeda T. Direct determination of bound sialic acids in sialoglycoproteins by acidic ninhydrin. Anal Biochem. 1989;179:332-5.

11. Gloria Calsina, Ramón JM, Echeverría JJ. Effects of smoking on periodontal tissues. J Clinical Periodontol. 2002;29(8):771-6.

12. AlSada AS. Elevated levels of salivary sialic acid in periodontitis disease. Iraqi National J Chemistry. 2010(40):736-41.

13. Rathod, SR, Khan, F, Kolte AP, Gupta M. Estimation of salivary and serum total sialic acid levels in periodontal health and disease. J Clin and Diagnostic Res. 2014;8(9):ZC19-21.

14. Moncla BJ, Braham P, Hillier S. Sialidase (neuraminidase) activity among gram-negative anaerobic and capnophilic bacteria. J Clinical Microbiol. 1990;28(3):422-5.

15. Shetty PK, Pattabiraman TN. Salivary glycoproteins as indicators of oral diseases. Indian J Clin Biochemistry: IJCB. 2004;19(1):97-101.

16. Ahmed BM, Wsoo MA. Evaluation of salivary $\alpha$-L-Fucose and its related parameters in periodontitis. Zanco J Medical Sci. 2013;17(3):563-9.

17. Thompson S, Matta KL, Turner GA. Changes in fucose metabolism associated with heavy drinking and smoking: a preliminary report. Clinica Chimica Acta. 1991;201(1-2):59-64.

18. Henskens YM, Van der Velden U, Veerman EC, Amerongen AN. Protein, albumin and cystatin concentrations in saliva of healthy subjects and of patients with gingivitis periodonitis. J Periodontal Res. 1993;28(1):43-8.

19. Zuabi O, Machtei EE, Ben-Aryeh H, Ardekian L, Peled M, Laufer D. The effect of smoking and periodontal treatment on salivary composition in patients with established periodontitis. J Periodontol. 1999;70(10):12406.

20. Agnihotri R, Pandurang P, Kamath SU, Goyal R, Ballal S, Shanbhogue AY, et al. Association of cigarette smoking with superoxide dismutase enzyme levels in subjects with chronic periodontitis. J Periodontol. 2009;80(4):657-62.

21. Garg N, Singh R, Dixit J, Jain A, Tewari V. Levels of lipid peroxides and antioxidants in smokers and nonsmokers. J Periodontal Res. 2006;41(5):405-10.

22. Gutteridge JM. Lipid peroxidation and antioxidants as biomarkers of tissue damage. Clin Chemistry. 1995;41(12):1819-28.

23. Skalerič U, Kramar B, Petelin M, Pavllia Z, Wahl SM. Changes in TGF- $\beta 1$ levels in gingiva, crevicular fluid and serum associated with periodontal inflammation in humans and dogs. European $\mathbf{J}$ Oral Sci. 1997;105(2):136-42.

24. Haber J, Wattles J, Crowley M, Mandell R, Joshipura K, Kent RL. Evidence for cigarette smoking as a major risk factor for periodontitis. J Periodontol. 1993;64(1):16-23.

Bhagyalekshmi M | Volume 2; Issue 1 (2021) | JDHOR-2(1)-024 | Data Article

Citation: Bhagyalekshmi M, et al. Effect of Smoking and Periodontal Diseases on Salivary

Glycoconjugates and Oxidative Stress Markers-A Comparative Study. J Dental Health Oral Res.

2021;2(1):1-13.

DOI: http://dx.doi.org/10.46889/JDHOR.2021.2107 